\title{
Comparison of two pharmaceutical production processes using different eco-efficiency measuring methods
}

\author{
G. Van der Vorst ${ }^{1}$, W. Aelterman ${ }^{2}$, P. Van Broeck ${ }^{2}$, S. Walraedt ${ }^{3}$, \\ K. Schaerlaekens ${ }^{3}$, P. Stouthuyzen ${ }^{4}$, H. Van Langenhove ${ }^{1}$ \\ \& J. Dewulf ${ }^{1}$ \\ ${ }^{1}$ Ghent University, Belgium \\ ${ }^{2}$ Janssen Pharmaceutica, Belgium \\ ${ }^{3}$ Essenscia, Belgium \\ ${ }^{4}$ VITO, Belgium
}

\begin{abstract}
The rising importance of eco-efficiency in the chemical industry resulted in the development of a huge amount of measuring methods for the assessment of environmental and/or economical sustainability. In this presentation, a limited set of eco-efficiency measuring methods are illustrated for a case in the pharmaceutical industry. Different eco-efficiency measuring methods as, for example, exergy analysis, carbon footprint or ETH's Finechem tool, are used for the evaluation and comparison of a pharmaceutical batch production step and a continuous production step using a micro reactor. Data for both processes are delivered by Janssen Pharmaceutica (Belgium). First, this case allows one to make a comparative evaluation of the eco-efficiency of the pharmaceutical production options. Second, a thorough evaluation of the capabilities and advantages of the different eco-efficiency measuring methods can be made.

The evaluation of two pharmaceutical production alternatives based on different eco-efficiency measuring methods is a case study in the Eco ${ }^{2}$ chem project. In this $\mathrm{Eco}^{2} \mathrm{chem}$ project a structured evaluation of different ecoefficiency measuring methods for the chemical industry is made. The result of this $\mathrm{Eco}^{2} \mathrm{chem}$ project will be a web based eco-efficiency decision matrix allowing chemical companies to choose those eco-efficiency measuring methods which best fit the companies' needs.
\end{abstract}

Keywords: eco ${ }^{2}$ chem, eco-efficiency measuring methods, pharmaceutical production. 


\section{Introduction}

Currently, there is no need to convince the chemical industry of the necessity to shift towards more eco-efficient production processes and production technologies. Research in this area is twofold. First, research efforts are required concerning development of innovative chemical reactions and technologies. Second, there is a need for an adequate assessment of the eco-efficiency Van der Vorst et al. [4]. This assessment is necessary for better decision making, but it also allows better communication, be it for stimulating involvement of personnel or for external use. Assessing the eco-efficiency of processes and technologies can be done by different eco-efficiency measuring methods (EEMM's). A wide range of EEMM's are made available to the chemical industry by scientific institutes, academics as well as industry itself. It is the aim of the Eco ${ }^{2}$ chem Project, funded by European Regional Development Fund (ERDF) and the Flemish government, to develop a web based decision tool to help the chemical industry to select the EEMM which best fits the companies needs. In order to build this tool, a structured inventory of the existing EEMMs is made and a number of EEMM's is evaluated on real cases provided by the chemical industry. A limited set of eco-efficiency measuring methods are illustrated here for a case in the pharmaceutical industry. Eco-efficiency measuring methods as for example exergy analysis, carbon footprint, ETH's Finechem tool, life cycle assessment, E-factor etc. $[1-3,5]$ are used for the evaluation and comparison of a pharmaceutical batch production step and a continuous production step using a micro reactor. Data for both processes are delivered by Janssen Pharmaceutica (Belgium) [6].

\section{Materials and methods}

\subsection{Eco-efficiency measuring methods (EEMMs)}

For the evaluation of the eco-efficiency of both pharmaceutical production processes (batch vs. continuous), different EEMMs will be used. It is the purpose to calculate the eco-efficiency by using a wide range of different EEMMs and evaluate these results. Using this set of EEMMs will allow better understanding of the principles and possibilities of the EEMMs under consideration. This will contribute to the EEMM inventory to be made during the $\mathrm{Eco}^{2} \mathrm{chem}$ project and finally resulting in the Eco ${ }^{2}$ chem EEMM decision tool. The specific EEMMs used for this comparison (batch vs. continuous pharmaceutical production step) will be the E-factor, ETH's Finechem tool, exergy analysis at the process and the plant level, Cumulative Exergy Extracted from the Natural Environment (CEENE) method, carbon footprint (IPCC 2007 - GWP), Eco-indicator '99, ecological footprint and the cumulative energy demand (CED) [2-4, 7-10]. More information on EEMMs can be found in the references. 


\subsection{Pharmaceutical production processes: batch versus continuous production}

The case supplied by Janssen Pharmaceutica is the comparison of two alternatives for the sixth production step in the galantamine (anti-Alzheimer medication) production route. This sixth production step originally is a batch based production step, but can be replaced by a continuous production step using a micro reactor. In Figs. 1 and 2, an overview is given of the eight steps required

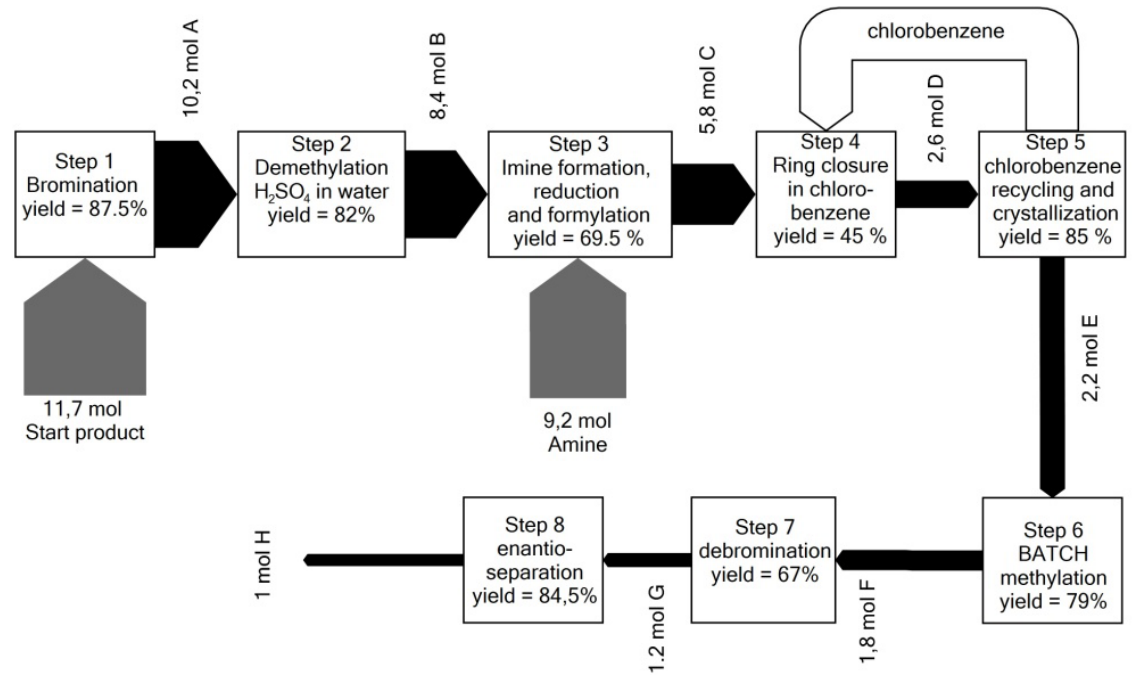

Figure 1: $\quad$ Synthesis route for the production of 1 mol intermediate $\mathrm{H}$ using the batch process in step 6 .

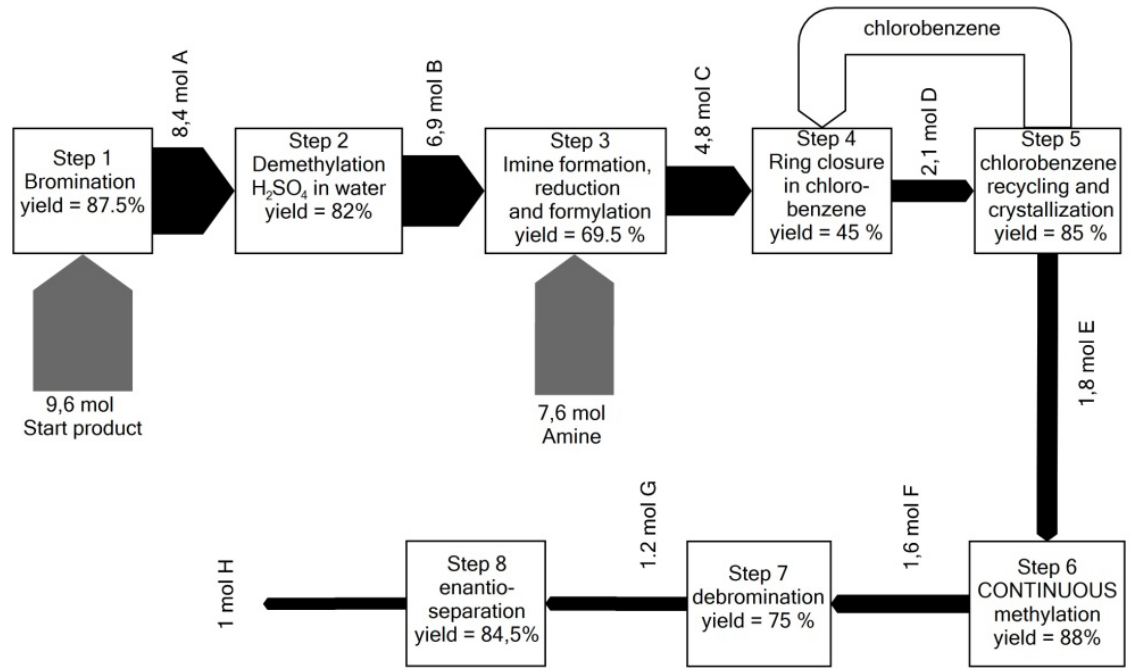

Figure 2: $\quad$ Synthesis route for the production of 1 mol intermediate $\mathrm{H}$ using the continuous process (micro reactor technology) in step 6. 
for the production of $1 \mathrm{~mol}$ of the galantamine intermediate $\mathrm{H}$. The evaluation by the different EEMMs is not limited to production step 6 but also shows the impact of taking into account the other steps of a pharmaceutical synthesis route. In Figs. 1 and 2, the improvement of the yield and its impact on the other production steps is illustrated.

The total data inventory required for the calculation of the used EEMMs, including all the mass and energy balances of all eight production steps is not given due to confidentiality issues and the overload of information.

\section{Results}

\subsection{E-factor}

The E-factor can be defined as the mass $(\mathrm{kg})$ waste produced per $\mathrm{kg}$ product. In Fig. 3 the E-factor of the 8 production steps individually is visualized. This means that the waste produced in earlier production steps is not taken into account. Changing process step 6 from a batch into a continuous process results in a drop of the E-factor from $29 \mathrm{~kg}$ waste $/ \mathrm{kg} \mathrm{F}$ to $19.5 \mathrm{~kg}$ waste $/ \mathrm{kg} \mathrm{F}$. This corresponds to a reduction of almost $50 \%$. In addition, small reductions due to the improved yields (see Figs. 1 and 2) can be seen in steps 7 and 8 . However, Fig. 3 also illustrates that step 4 as is the production step with the highest Efactor. This E-factor is mostly covered by the high amount of wastewater produced as well by the low efficiency of the process.

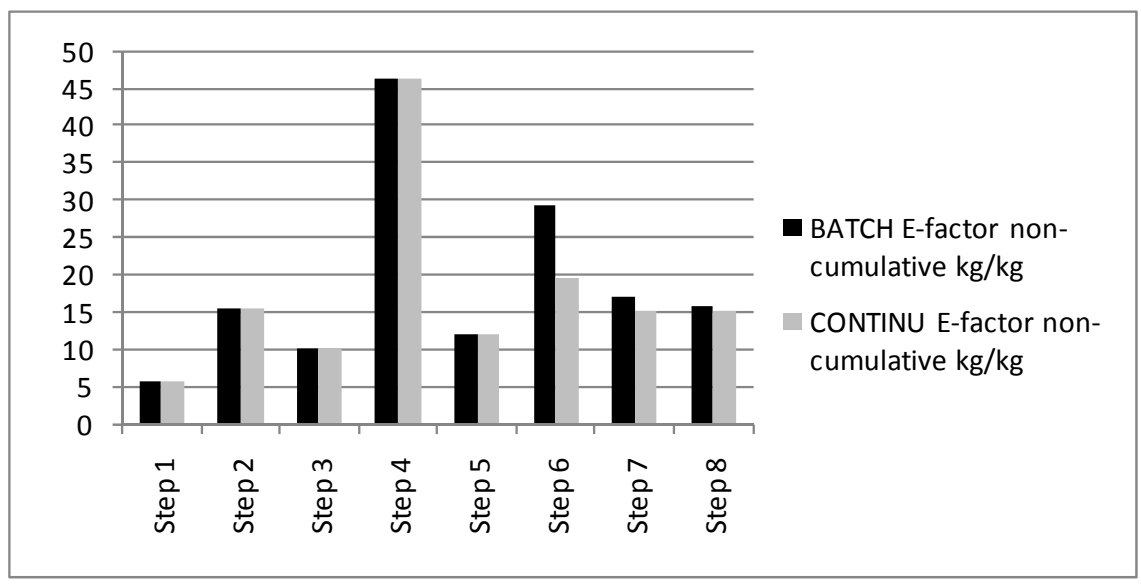

Figure 3: Non-cumulative E-factor of eight consecutive production steps.

In Fig. 4, the E-factors are cumulated. For each production step, the waste produced in the previous production step is taken into account. It can be seen that the reduction in the E-factor at step 6 by changing from batch to continuous is relatively small compared to the non-cumulative results. However, the difference increases again when taking into account steps 7 and 8. From these cumulative 


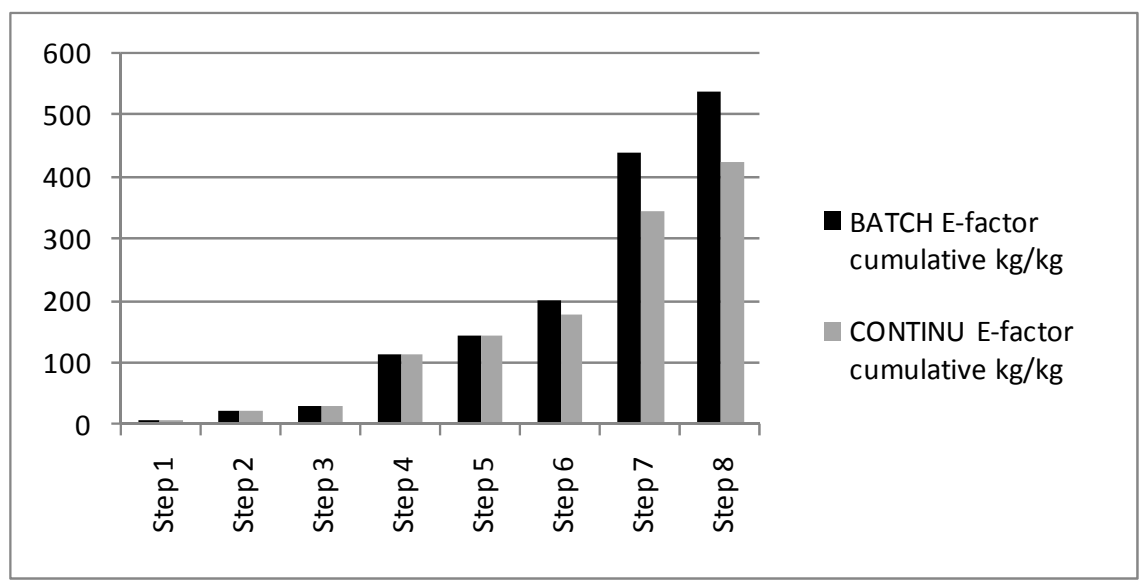

Figure 4: Cumulative E-factor of eight consecutive production steps.

results, it can be stated that in total $26 \%$ less waste is produced by using the continuous alternative in step 6 .

\subsection{ETH Finechem tool}

The Finechem tool from ETH is an estimation tool for the prediction of the cumulative energy demand (CED), the global warming potential (GWP) and the eco-indicator '99 (EI99) based on the group contributions of the chemicals under consideration. This tool cannot be used for the estimation of the life cycle impact assessment (LCIA) of enantiomers and components containing bromine atoms. This means it is not a useful EEMM for the evaluation of this case. This is also clear from the results presented in Fig. 5 where the tool is used for illustration. From step 5 (molecule E) on, the environmental impacts do not increase anymore, which is impossible regarding the efficiencies in Figs. 1 and Fig. 2. The ETH Finechem tool however remains a very good estimation tool if no other data is available and as long as the guidelines are followed correctly, which is clearly not the case for this illustration.

\subsection{Exergy analysis (process and plant level)}

Next to the relatively quick EEMMs (E-factor and ETH finechem tool), more detailed but also more time consuming EEMMs can be used for the evaluation of chemical production processes. One example is the exergy analysis of the eight process steps at the process level and at the plant level. The focus here will only be on the results of plant level exergy analysis. Non-cumulative results at the plant level are presented in Fig. 6 and cumulative results are presented in Fig. 7. Those figures are similar to the ones presented for the E-factor (Figs. 3 and 4) because the main contributor of all the environmental impacts in these processes is the use of fossil chemicals (visible in Figs. 6 and 7). However, when Figs. 3 and 6 are put next to each other, the importance of step 4 in Fig. 3 has 
16 Sustainable Chemistry

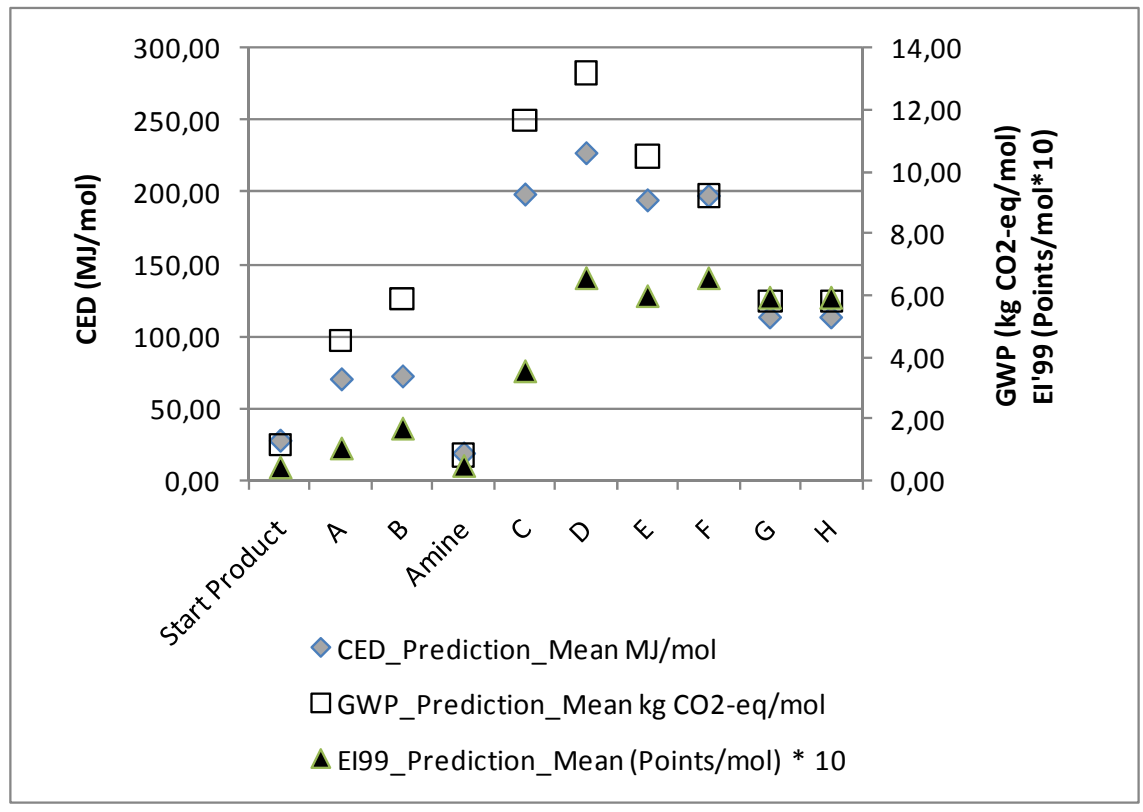

Figure 5: ETH prediction of ten intermediate molecules in the synthesis route of galantamine.

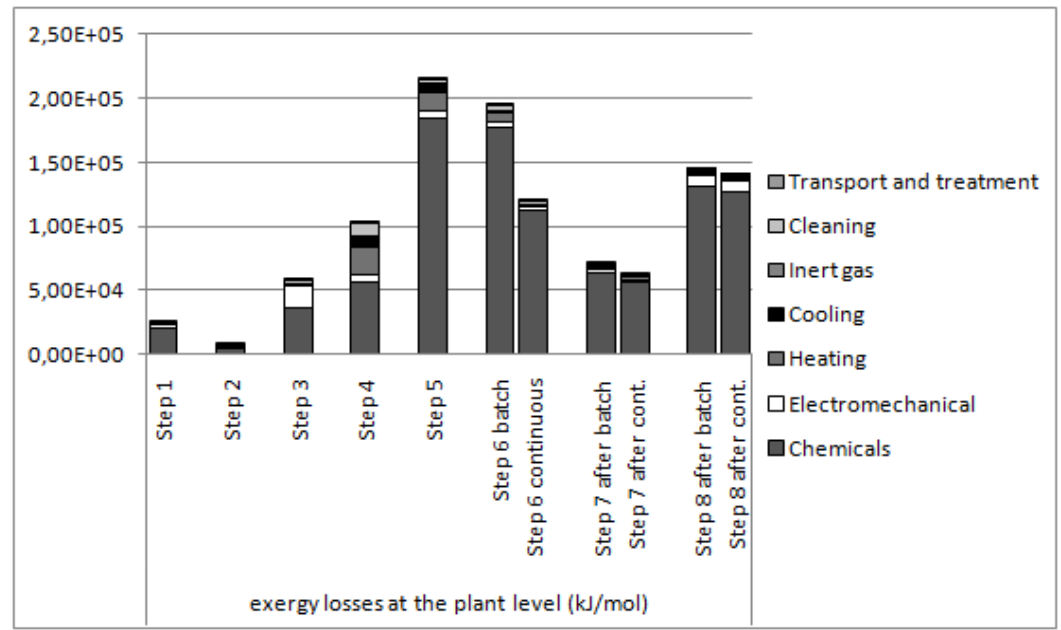

Figure 6: Non cumulative exergy losses at the plant level for eight consecutive production steps and divided over seven impact categories. 


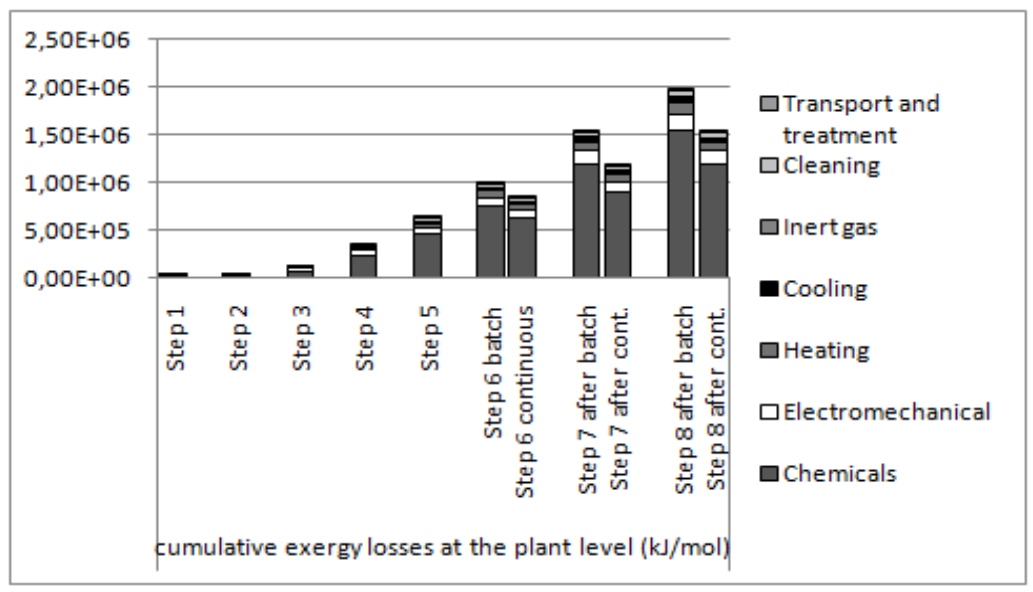

Figure 7: Cumulative exergy losses at the plant level for eight consecutive production steps and divided over seven impact categories.

disappeared in Fig. 6. The reason is that in the E-factor EEMM, one kg water has the same impact as one $\mathrm{kg}$ organic solvent. This is not the case using exergy analysis. The waste stream of step 4 is mainly water based and thus scores worse for the E-factor than for an exergy analysis. Coming back to the comparison of batch and continuous however, in Figs. 6 and 7, again the improvement of changing the process is clear and lies in the same order of magnitude as for the E-factor EEMM results.

\subsection{Data intensive life cycle based evaluations (CEENE, CED, EI'99, IPCC 2007, EF)}

The last evaluated EEMMs are grouped as life cycle based EEMMs and this includes EEMMs taking into account the full cradle-to-gate of the pharmaceutical production steps. Taking into account the full cradle-to-gate means more intensive data inventory is required. Similar as the results of the exergy analysis at the plant level, results can be presented (Fig. 8) by using the CEENE method at the cradle-to-gate level. In the exergy analysis at the plant level (Fig. 7), the resource consumption (exergy losses) were attributed to the sinks were they are used (lost). In the CEENE method, however, the resource consumption can also be attributed to the source the resources are coming from. As stated before, the highest impacts in Fig. 7 are linked to the use of fossil chemicals. This is confirmed in Fig. 8. The four other life cycle based EEMMs evaluated here show similar profiles with similar ratios between the process steps as presented in Fig. 8. In Table 1, the results of all the life cycle based EEMMs are presented and the improvements made by changing from batch to continuous production is given for the cumulative results of $1 \mathrm{~mol} \mathrm{~F}$ (stopping the evaluation after step 6) as well as for the cumulative results of $1 \mathrm{~mol} \mathrm{H}$ (stopping the evaluations after step 8). First, it is clear that the improvements expressed in 
Table 1: $\quad$ Impact reductions at step 6 and at step 8 for the five life cycle impact assessment methods.

\begin{tabular}{|c|c|c|c|c|c|c|}
\hline & $\begin{array}{l}\text { BATCH } \\
1 \mathrm{~mol} \mathrm{~F}\end{array}$ & $\begin{array}{l}\text { CONTINU } \\
1 \mathrm{~mol} \mathrm{~F}\end{array}$ & $\begin{array}{l}\text { Impact } \\
\text { reduction }\end{array}$ & $\begin{array}{l}\text { BATCH } \\
1 \mathrm{~mol} \mathrm{H}\end{array}$ & $\begin{array}{l}\text { CONTINU } \\
1 \mathrm{~mol} \mathrm{H} \\
\end{array}$ & $\begin{array}{c}\text { Impact } \\
\text { reduction }\end{array}$ \\
\hline CEENE (kJ) & 2,97E+06 & $2,54 \mathrm{E}+06$ & $16,75 \%$ & $5,64 \mathrm{E}+06$ & $4,39 \mathrm{E}+06$ & $28,54 \%$ \\
\hline Carbon footprint IPCC GWP 2007 100a (kg CO2-eq) & $9,99 \mathrm{E}+01$ & $8,39 E+01$ & $19,10 \%$ & $1,88 \mathrm{E}+02$ & $1,43 E+02$ & $31,24 \%$ \\
\hline Cumulative energy demand (total) (MJ-eq) & $2,48 \mathrm{E}+03$ & $2,12 \mathrm{E}+03$ & $16,96 \%$ & $4,71 E+03$ & $3,65 E+03$ & $28,89 \%$ \\
\hline Ecoindicator El'99 (H/A) total (points) & $1,01 \mathrm{E}+01$ & $8,61 \mathrm{E}+00$ & $17,03 \%$ & $1,88 \mathrm{E}+01$ & $1,46 \mathrm{E}+01$ & $29,33 \%$ \\
\hline Ecological footprint (total) $\left(\mathrm{m}^{2} \mathrm{a}\right)$ & $2,66 \mathrm{E}+02$ & $2,25 \mathrm{E}+02$ & $18,40 \%$ & $5,03 E+02$ & $3,86 \mathrm{E}+02$ & $30,41 \%$ \\
\hline
\end{tabular}

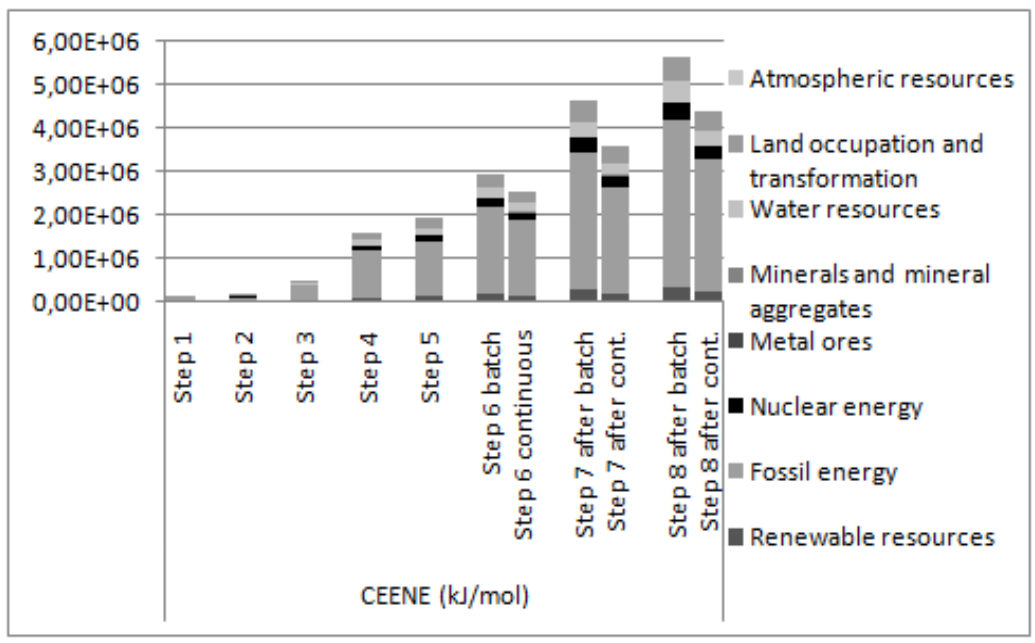

Figure 8: $\quad$ CEENE of the eight production steps (cumulative results).

percentages are similar for all 5 life cycle impact assessment methods. Reason is the use of organic solvents in all production steps. Second, it is clear that the improvements quantified in percentages can change significantly (from $18 \%$ up to $30 \%$ ) if more consecutive production steps (step 6 up to step 8 ) are taken into account. This is related to the cumulative effect of taking into account the yields of the consecutive production steps.

\section{Conclusions and outlook}

Regarding the pharmaceutical production process evaluation, it can be concluded that for all the EEMMs used, the continuous alternative is better from an ecoefficiency point of view than the batch production process. Improvements ranging from 16 up to $50 \%$ are quantified depending on the used EEMM and the used boundaries (cumulative, non cumulative, process level, plant level, cradleto-gate level).

Regarding the evaluation of the different used EEMMs, many different results can be obtained depending on the used eco-efficiency methodology. Although in this case all results were in favour of the continuous alternative, it can happen 
that for other cases the results will not be that obvious. Therefore it remains important to use the best EEMM for the purpose the user wants to have results for. Quick scans as the E-factor require less input which results in higher uncertainty on the results. The more detailed EEMMs are on the other hand more time-consuming. A good EEMM selection has to take into account these issues. It is also important to thoroughly study the limitations of different EEMM. If EEMMs (e.g. ETH finechem tool) limitations are not considered, big errors can be made without knowing.

Regarding the further outlook of the $\mathrm{Eco}^{2} \mathrm{chem}$ project, more cases are to be calculated for a better evaluation of a wider range of EEMMs. These results will finally contribute to a good evaluation and better understanding of the capabilities and limitations of the inventoried EEMMs. This knowledge will be applied in the development of the decision tool.

\section{References}

[1] Dewulf, J., Van Langenhove, H., Muys, B., Bruers, S., Bakshi, B.R., Grubb, G.F., Paulus, D.M. and Sciubba, E., Exergy: Its potential and limitations in environmental science and technology. Environmental Science \& Technology, 42, pp. 2221-2232, 2008.

[2] BSI , PAS 2050 (2008) Specification for the assessment of the life cycle greenhouse gas emissions of goods and services, www.bsigroup.com /Standards-and-Publications/How-we-can-help-you/Professional-StandardsService/PAS-2050

[3] ETH Finechem tool, www.sust-chem.ethz.ch/tools/finechem/

[4] Van der Vorst, G., Van Langenhove, H., De Paep, F., Aelterman, W., Dingenen, J., Dewulf, J., Exergetic Life Cycle analysis for the selection of chromatographic separation processes in the pharmaceutical industry: preparative HPLC versus preparative SFC. Green Chemistry, 11, pp. 10071012, 2009.

[5] European Commission - Joint Research Center, Life Cycle Thinking and Assessment, http://lct.jrc.ec.europa.eu/

[6] Janssen Pharmaceutica, www.janssenpharmaceutica.be

[7] Constable, D., Curzons, A., Cunningham, V., Metrics to 'green' chemistry - Which are the best? Green Chemistry, 4, pp. 521-527, 2002.

[8] Dewulf, J., Bosch, M.E., De Meester, B., Van der Vorst, G., Van Langenhove, H., Hellweg, S., Huijbregts, M., Cumulative exergy extraction from the natural environment (CEENE): a comprehensive life cycle impact assessment method for resource accounting. Environmental Science \& Technology, 41(24), pp. 8477-8483, 2007.

[9] Huijbregts, M., Hellweg, S., Frischknecht, R., Hungerbuehler, K., Hendriks, A., Ecological footprint accounting in the life cycle assessment of products. Ecological Economics, 64 (4), pp. 798-807, 2008.

[10] Huijbregts, M., Rombouts, L., Hellweg, S., Frischknecht, R., Hendriks, A., Van de Meent, D., Ragas, A., Reijnders, L., Struijs, J., Is cumulative fossil energy demand a useful indicator for the environmental performance of products, Environmental Science \& Technology, 40(3), 641-648, 2006. 